\title{
TYLANTHIDIUM, GEN.N. DE ANTHIDIINAE DA AMÉRICA DO SUL (HYMENOPTERA, MEGACHILIDAE) E NOTA TAXONÔMICA
}

\author{
Danúncia Urban ${ }^{2}$
}

\begin{abstract}
TYLANTHIDIUM, GeN.N. OF ANTHIDINE From SOUTH AMERICA (HYMENOPTERA, MEgaCHILIDAE) AND A TAXONOMIC NOTE. Tylanthidium, gen.n. is proposed to a new species from the north brazilian state of Amazonas - Tylanthidium tuberigaster, sp.n. - characterized by the absence of arolia and of interalveolar carinas, the peculiar scutellum almost triangular and by the genal preoccipital carinae: the males with the apical border of the mandibles deeple sinuate and the distal tergum densely hairy bellow. Michanthidium nom.n. is given to Gnathanthidium Urban, 1992 (non Gnathanthidium Pasteels, 1969).

KEY WORDS. Hymenoptera, Anthidiinae, Magachilidae, Tylanthidium, taxonomic note
\end{abstract}

Tylanthidium, gen.n. de Dianthidiini é proposto para uma espécie nova do norte do Brasil (Amazonas, Manaus) - Tylanthidium tuberigaster, sp.n., cujas principais características são: ausência de arólios e de carenas interalveolares, a forma peculiar do escutelo sub-triangular estreitamente truncado-chanfrado e fortemente projetado para trás, e a presença de carena pré-ocipital nas genas. Os machos são reconhecidos também pelas mandibulas somente com o bordo apical fortemente sinuado, pelo tergo distal espatulado-chanfrado densamente piloso por baixo e o segundo esterno com duas grandes projeções tuberculiformes de ápice truncado. Fêmeas com mandíbulas fracamente quadridentadas.

\section{Tylanthidium, gen.n.}

Espécie tipo Tylanthidium tuberigaster, sp.n.

Macho. Tegumento brilhante densamente pontuado, os pontos menores e mais numerosos na fronte, vértice e mesoscuto ( 70 micra), bem maiores no escutelo e nos mesepisternos; pontos esparsos nos tergos porém menores do que nos mesepisternos; flancos do propódeo e metade ventral dos metepisternos praticamente sem pontos. Pilosidade muito curta, os pêlos igualando o diâmetro do ocelo mediano ou menores, longa nos cantos dos tergos e nos esternos.

Mandíbulas com o bordo apical fortemente sinuado (Fig. 1), área deprimida junto à base, o tegumento brilhante com pontuação alongada e com duas carenas curtas no lado externo inferior; palpos maxilares com pêlos longos desde a base;

1) Contribuição número 796 do Departamento de Zoologia, Universidade Federal do Paraná.

2) Departamento de Zoologia, Universidade Federal do Paraná, Caixa Postal 19020, 81531-970 Curitiba, Paraná, Brasil. 
clípeo quase achatado, deprimido no ápice e sem tubérculos, somente com pequenas formações irregulares no ápice, fracamente emarginado quase até os cantos, estes retos não sobressaindo à base do labro; suturas subantenais fracamente arqueadas; sem carenas interalveolares e sem carena frontal; carenas paroculares fortes porém não chegando ao vértice; genas largas separadas do ocipício por forte carena pré-ocipital nos dois terços superiores; carena hipostomal forte; antenas com o escapo mais longo que a distância interalveolar, com os dois flagelômeros basais muito curtos e somente o apical mais longo que seu diâmetro.

Pronoto com lamela curta nos lobos, arqueada e terminando em fraca depressão antes do mesoscuto; mesepisternos com carena pré-episternal curta ocupando o terço dorsal; mesoscuto expandido lateralmente em lâmina voltada para cima; escutelo sub-triangular estreitamente truncado-chanfrado e fortemente projetado para trás, expandido em lamela e sobressaindo bastante ao metanoto, em vista posterior côncavo; mesoscuto, escutelo e axilas quase no mesmo plano; base do escutelo largamente deprimida e brilhante entre as axilas, não dividida; axilas projetadas largamente para trás porém não carenadas nem expandidas em lamela translúcida (Fig. 4); tégulas arredondadas posteriormente; asas anteriores com a bifurcação entre a média e o cúbito posterior à veia transversal cúbito-anal; asas posteriores com o lobo jugal pouco menor que a metade do lobo anal; tarsômeros das pernas anteriores e medianas com pilosidade alongada e mais densa no bordo posterior; mediotarsos muito curtos nas pernas anteriores, nas medianas alongados e cordiformes e nas posteriores com projeção dentiforme no lado posterior, mais longa no mais distal; sem arólio entre as garras.

Propódeo vertical com fovéolas basais maiores que o comprimento do metanoto medianamente, porém aumentando de tamanho para os lados onde alcançam quase o dobro do comprimento das fovéolas medianas; espiráculo propodeal carenado com larga área retangular posterior brilhante e com microreticulação, sem fovéolas, extendendo-se até a metade do espiráculo e outra área mais ventral porém aberta posteriormente; tergos com depressão marginal estreita nos flancos do primeiro ao quinto; sexto pouco deprimido na margem e o sétimo tergo (Fig. 5) espatulado-chanfrado e densamente piloso ventralmente; esterno basal com carena laminada mediana alta e translúcida no terço basal, para o disco com duas carenas baixas divergentes e mais infladas na ponta, bordo apical fracamente bi-sinuado; segundo esterno com uma larga projeção tuberculiforme (Figs 3 e 6) a cada lado no disco, com o bordo truncado e a face posterior levemente côncava; terceiro ao quinto esterno com pêlos longos semi-eretos; sexto com o ápice truncado.

Fêmea. Semelhante ao macho, difere nas estruturas abaixo relacionadas: mandíbulas (Fig. 2) fracamente quadridentadas com carenas látero-external e externa-inferior curtas; depressão marginal estreita nos cantos do primeiro ao quinto tergo; sexto tergo sem carena média, um pouco deprimido no disco e elevado para o ápice; sexto esterno normal; pernas normais, sem arólio; coxas anteriores com espinho apical curto densamente piloso; lado externo das tíbias medianas com projeção apical espiniforme proeminente delgada; parte ventral dos mesepisternos e parte das pernas com pilosidade curta, fina e densa, de ápice enrolado em gancho; 
pilosidade curta e cerdosa nas tíbias e nos basitarsos medianos e posteriores, mais densa no lado externo dos medianos.

A ausência de arólios aproxima Tylanthidium de Hypanthidium Cockerell, 1904 e de Saranthidium Moure \& Hurd 1960 porém a forma do sétimo tergo, espatulado-chanfrado e projetado para trás e a ausência de carenas interalveolares separam estes dois gêneros de Saranthidium que é caracterizado pelas fortes carenas interalveolares e pelo sétimo tergo profundamente bilobado e com lâmina somente nos lobos. Hypanthidium não tem carenas genais, o escutelo pouco projetado não triangular e em vista posterior côncavo aos lados e mais estreito no meio; os machos com três dentes apicais nas mandíbulas e sem tubérculos discais no segundo esterno. O sétimo tergo de Tylanthidium é mais longo do que em Hypanthidium, sem depressão subapical e alargando para o ápice.

O nome do gênero refere-se aos tubérculos abdominais.

\section{Tylanthidium tuberigaster, sp.n.}

Figs $1-6$

Diagnose. Macho com áreas pretas e amarelas na cabeça, estria estreita amarela nos lados do mesoscuto e com o escutelo e as axilas em grande parte amarelos; dois tergos basais com nódoas laterais amarelas e do terceiro ao sexto com faixa amarela discal, mais larga no sexto. Fêmea com as áreas amarelas da cabeça mais reduzidas que no macho; mandibulas amarelas na metade basal; mesoscuto, escutelo, axilas e as faixas amarelas abdominais como no macho, porém no sexto tergo larga e não expandida aos lados.

Holótipo macho. Tegumento predominante preto com as seguintes áreas amarelas: lado externo das mandíbulas porém os dentes e a orla enegrecidos; clípeo amarelo com grande nódoa preta desde a base e ocupando grande parte do disco: larga faixa nas paroculares inferiores estreitando muito na altura da tangente inferior dos alvéolos antenais e terminando abaixo do nível do ocelo médio; estreita faixa na metade posterior do vértice prolongada nas genas até a metade do comprimento dos olhos; escapo amarelo anteriormente e restante dos flagelômeros castanho, um pouco mais claro no apical. Mesoscuto com estria amarela fina aos lados prolongada anteriormente em faixa lateral um pouco mais larga; mesepisternos com nódoa amarela arredondada; escutelo e axilas com larga margem amarela e área basal preta mais larga no meio do escutelo; pernas castanhas, coxas com área anterior amarela; fêmures anteriores e medianos com estria amarela e os posteriores somente com nódoa distal desta cor; basitarsos anteriores amarelados na face anterior, tíbias e fêmures anteriores de um amarelo acastanhado na face anterior. Tergos castanho-enegrecidos com larga orla translúcida castanha e nódoas amarelas laterais um pouco alongadas para o disco nos dois basais; do terceiro ao sexto com faixa discal amarela, mais larga no meio do quinto e no sexto reduzindo a área escura à base e ao ápice do tergo; sétimo com duas nódoas laterais amarelas quase até o ápice e larga margem translúcida castanha clara; esternos castanhos, o primeiro com duas pequenas manchas amarelas aos lados e o segundo com os tubérculos laterais de um amarelo claro. 

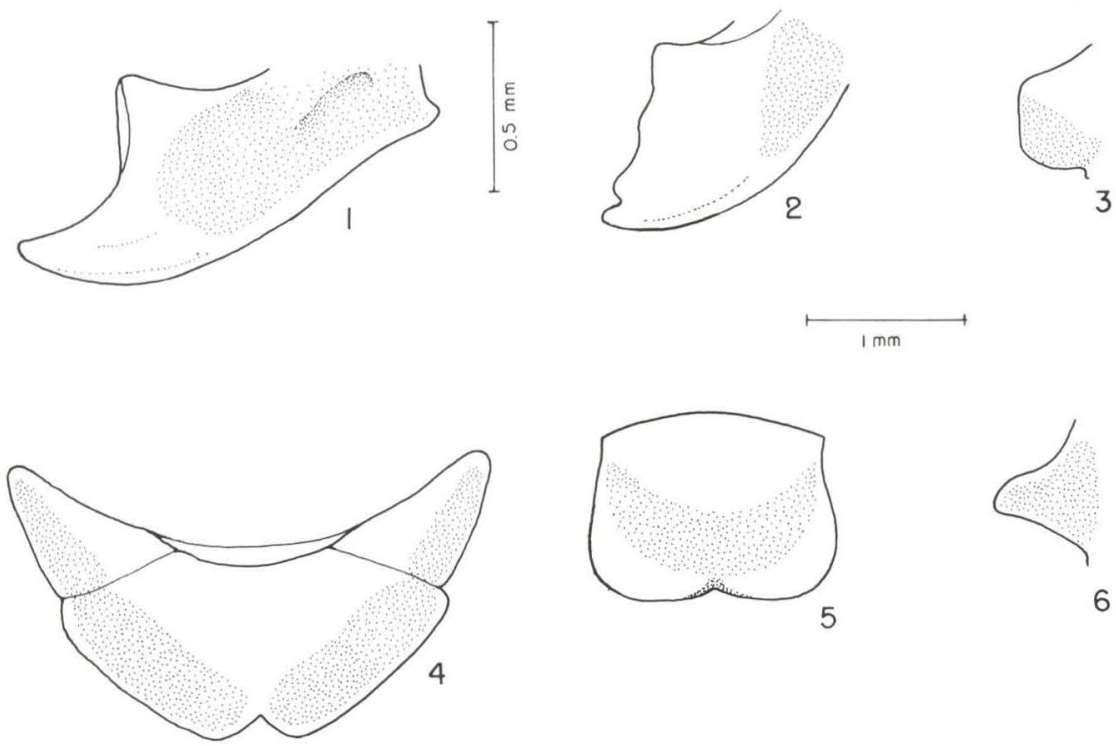

5

6

Figs 1-6. Tylanthidium tuberigaster, sp.n. (1) Mandỉula do macho; (2) mandỉula da fềmea; (3) vista anterior do tubérculo do segundo esterno do macho; (4) escutelo e axilas; (5) ápice do sétimo tergo do macho; (6) tuhérculo do segundo esterno em vista de perfil. Em pontilhado o tegumento amarelo. Figuras I e $2 \mathrm{com}$ maior aumento.

Comprimento aproximado $10,67 \mathrm{~mm}$; comprimento da asa anterior a partir do esclerito costal $9,17 \mathrm{~mm}$; largura da cabeça $3,58 \mathrm{~mm}$; comprimento do olho $2,52 \mathrm{~mm}$. No parátipo comprimento do olho $2,42 \mathrm{~mm}$; distância interorbital superior $1,67 \mathrm{~mm}$ e a inferior $1,42 \mathrm{~mm}$.

Alótipo fêmea. Cabeça preta com as seguintes áreas amarelas: grande mancha no lado externo das mandibulas até a base; duas nódoas laterais subapicais no clípeo; estria estreita nas paroculares, mais delgadas superiormente e terminando bem abaixo do ocelo médio; faixa estreita na área posterior do vértice interrompida atrás dos olhos. Mesepisternos pretos; mesoscuto e escutelo como no macho porém as estrias laterais do mesoscuto mais estreitas e um pouco enegrecidas. Primeiro ao quinto tergo como no macho; sexto tergo preto nos lados e na margem onde se alarga um pouco para o meio, no disco e basalmente amarelo.

Escopa esbranquiçada amarelenta.

Comprimento aproximado $8,83 \mathrm{~mm}$; comprimento da asa anterior a partir do esclerito costal $7,00 \mathrm{~mm}$; largura da cabeça $3,25 \mathrm{~mm}$; comprimento do olho $2,42 \mathrm{~mm}$; distância interorbital superior $1,80 \mathrm{~mm}$ e a inferior $1,52 \mathrm{~mm}$.

Holótipo macho com a seguinte etiqueta: Manaus-AM/Brasil-VIII-59/C. Elias leg. Alótipo fềmea da mesma localidade e coletado em maio de 1959 por C. Elias. Um parátipo macho coletado em 10.VIII.1955 e uma fềmea coletada em 
29.XI. 1958 por Elias e Roppa. Depositados na Coleção de Entomologia Pe. Jesus Santiago Moure, Departamento de Zoologia, Universidade Federal do Paraná.

Distribuição geográfica. BRASIL, Amazonas: Manaus.

Variação. No parátipo macho o sétimo tergo com área discal amarela em forma de faixa deixando larga margem translúcida castanha amarelada.

\section{NOTA TAXONÔMICA}

\section{Michanthidium, nom.n.}

Gnathanthidium Urban, 1992: 338 (non Gnathanthidium Pasteels, 1969: 92).

A descoberta da homonímia foi feita pelo Dr. Charles D. Michener, da Universidade de Kansas, que imediatamente transmitiu a informação, a quem agradeço. Renomeio esse gênero em sua homenagem.

\section{REFERÊNCIAS BIBLIOGRÁFICAS}

PASTEels, J.J. 1969. La Systematique generique et subgenerique des Anthidiinae (Hymenoptera, Apoidea, Megachilidae) de l'Ancien Monde. Mem. Soc. R. Ent. Belg. 31: 1-146.

Urban, D. 1992. Gnathanthidium, gen.n. de Anthidiinae da América do Sul (Hymenoptera, Megachilidae). Revta bras. Zool. 9 (3/4): 337-343.

Recebido em 10.III.1994: aceito em 15.V.1994. 